\title{
Critical illness induces alternative activation of M2 macrophages in adipose tissue
}

Lies Langouche ${ }^{1 *}$, Mirna B Marques ${ }^{1}$, Catherine Ingels ${ }^{1}$, Jan Gunst ${ }^{1}$, Sarah Derde ${ }^{1}$, Sarah Vander Perre ${ }^{1}$, André D'Hoore ${ }^{2}$ and Greet Van den Berghe ${ }^{1}$

\begin{abstract}
Introduction: We recently reported macrophage accumulation in adipose tissue of critically ill patients. Classically activated macrophage accumulation in adipose tissue is a known feature of obesity, where it is linked with increasing insulin resistance. However, the characteristics of adipose tissue macrophage accumulation in critical illness remain unknown.

Methods: We studied macrophage markers with immunostaining and gene expression in visceral and subcutaneous adipose tissue from healthy control subjects $(n=20)$ and non-surviving prolonged critically ill patients $(n=61)$. For comparison, also subcutaneous in vivo adipose tissue biopsies were studied from 15 prolonged critically ill patients.
\end{abstract}

Results: Subcutaneous and visceral adipose tissue biopsies from non-surviving prolonged critically ill patients displayed a large increase in macrophage staining. This staining corresponded with elevated gene expression of "alternatively activated" M2 macrophage markers arginase-1, IL-10 and CD163 and low levels of the "classically activated" M1 macrophage markers tumor necrosis factor (TNF)- $\alpha$ and inducible nitric-oxide synthase (iNOS). Immunostaining for CD163 confirmed positive M2 macrophage staining in both visceral and subcutaneous adipose tissue biopsies from critically ill patients. Surprisingly, circulating levels and tissue gene expression of the alternative M2 activators IL-4 and IL-13 were low and not different from controls. In contrast, adipose tissue protein levels of peroxisome proliferator-activated receptor- $\gamma$ (PPAR $\gamma$ ), a nuclear receptor required for M2 differentiation and acting downstream of IL-4, was markedly elevated in illness. In subcutaneous abdominal adipose tissue biopsies from surviving critically ill patients, we could confirm positive macrophage staining with CD68 and CD163. We also could confirm elevated arginase-1 gene expression and elevated PPARr protein levels.

Conclusions: Unlike obesity, critical illness evokes adipose tissue accumulation of alternatively activated M2 macrophages, which have local anti-inflammatory and insulin sensitizing features. This M2 macrophage accumulation may contribute to the previously observed protective metabolic activity of adipose tissue during critical illness.

\section{Introduction}

In our previous study on the role of adipose tissue during critical illness, we reported a remarkable accumulation of macrophages in adipose tissue of prolonged critical ill patients and prolonged critically ill rabbits [1]. Such sudden accumulation of adipose tissue macrophages is a known feature of obesity, where it is linked with increased insulin resistance [2,3]. Recent findings

\footnotetext{
* Correspondence: lies.langouche@med.kuleuven.be

'Laboratory and Department of Intensive Care Medicine, K.U.Leuven, Herestraat 49, 3000 Leuven, Belgium

Full list of author information is available at the end of the article
}

demonstrate that adipose tissue of healthy, lean individuals contains a resident population of "alternatively activated" or M2 macrophages, whereas obesity related adipose tissue expansion appears to induce an infiltration of "classically activated" or M1 macrophages $[4,5]$. These M1 macrophages produce pro-inflammatory cytokines, such as tumor necrosis factor alpha (TNF- $\alpha$ ), thereby contributing to a local and systemic chronic inflammatory status and insulin resistance [2-5]. In obesity, the increase in adipocyte cell size is suggested to be the trigger for this macrophage accumulation, as there is

\section{Biomed Central}


a strong positive correlation between adipocyte cell size and the amount of macrophages [2,3].

Why critical illness appears to be associated with increased infiltration of macrophages in adipose tissue is not clear. In contrast with obesity, critical illness induced a decrease in adipocyte cell size [1]. Furthermore, whether critical illness induces an increase in M1 or M2 macrophages in adipose tissue remains to be identified. M1 macrophages are mainly activated by interferon-gamma (IFN- $\gamma)$. They have an enhanced proinflammatory cytokine production (TNF- $\alpha$, IL-6, IL-12) and generate excessive nitric oxide levels through inducible nitric-oxide synthase (iNOS) activation. In contrast, macrophages are polarized to the M2 state by IL- 4 and IL-13. M2 macrophages secrete high levels of the antiinflammatory cytokine IL-10 and produce arginase-1, which metabolizes arginine to ornithine. By directly competing for the substrate arginine, activation of arginase-1 will also antagonize iNOS action [6,7].

We previously reported that adipose tissue from critically ill patients displayed a larger number of small adipocytes in response to critical illness, with an increased ability to take up circulating glucose and triglycerides [1]. These changes rather point to increased insulin sensitivity in the adipose tissue and would contradict with a local increase of pro-inflammatory, TNF- $\alpha$ producing M1 macrophages. Therefore, we hypothesized that critical illness induces an accumulation of anti-inflammatory, insulin sensitizing M2 macrophages. To determine the characteristics of the macrophage accumulation in adipose tissue of the critically ill, we studied abdominal subcutaneous and visceral adipose tissue biopsies and serum of 61 non-surviving prolonged (more than three days) critically ill patients and 20 demographically matched controls. Finally, we confirmed our findings in 15 in vivo sampled abdominal adipose tissue needle biopsies from prolonged critically ill patients.

\section{Materials and methods Patients}

Postmortem biopsy samples of abdominal subcutaneous and omental adipose tissue were harvested within minutes after death from 61 long-stay critically ill patients with an intensive care unit (ICU) stay of at least three days. Patients were all enrolled in a large prospective, randomized controlled study on the effects of intensive insulin therapy on outcome of critical illness [8]. The detailed protocol of the study has been previously published [8]. We collected biopsies from 33 conventionally treated patients and 28 samples from intensive insulin treated patients. For postmortem tissue sampling for academic purposes, each patient or his/her legal representative consented upon admission, via a hospital-wide information and consent procedure, which requires active opting-out when not consenting. Opting-out remained possible until time of death. This strategy was approved by the Institutional Ethical Review Board (ML1820). The baseline and outcome characteristics of the critically ill patients from whom postmortem adipose tissue biopsies were collected, are described in Table 1. For comparison, we also collected abdominal subcutaneous and omental adipose tissue biopsy samples from demographically matched patients, who were not critically ill, and who underwent elective abdominal surgery for restorative rectal resection (ML 2707). These patients provided written informed consent prior to the procedure. From 15 long-stay patients, we collected in vivo abdominal subcutaneous adipose tissue needle biopsies on Day 7 of their ICU stay. The in vivo biopsies were taken after a specific written informed consent from the patient or his/her legal representative (ML 4190). The baseline characteristics of the critically ill patients from whom in vivo adipose tissue biopsies were collected are described in Table 2. The protocols and all consent forms were approved by the Institutional Ethical Review Board (ML 1820 and ML 2707, ML 4190). All tissue samples were snap-frozen in liquid nitrogen and stored at $-80^{\circ} \mathrm{C}$ until analysis.

\section{Adipocyte morphology}

Tissue samples were fixed in 6\% paraformaldehyde overnight. Paraffin wax sections of $6 \mu \mathrm{m}$ were processed for immunostaining. Sections were stained with a primary anti-macrophage CD68 antibody (Dako, Glostrup, Denmark) and CD163 antibody (Santa Cruz Biotechnology, Santa Cruz, CA, USA) and counterstained with hematoxylin. Staining was evaluated at a $10 \times$ and $40 \times$ magnification using a Leica DM3000 Microscope (Leica, Wetzlar, Germany).

\section{Gene expression}

Tissue samples were homogenized with a Precellys 24 machine using CK14 tubes (Bertin Technologies, Villeurbanne, France) containing ceramic beads at 6,500 rpm for one cycle of $45 \mathrm{sec}$ in Qiazol (Qiagen, Hilden, Germany). RNA was isolated using the RNeasy mini RNA isolation kit (Qiagen) and quantified by Nanodrop spectrophotometer (ND-1000, Nanodrop Technologies, Wilmington, DE, USA). Samples were treated with DNAse to remove all contaminating genomic DNA. A total of 500 to $250 \mathrm{ng}$ of total RNA was reverse-transcribed using Superscript III Reverse Transcriptase (Invitrogen, Merelbeke, Belgium) and random primers (Invitrogen). In a first run, all postmortem samples and healthy controls were reverse transcribed simultaneously. In a second run, all in vivo samples and healthy controls were reverse transcribed simultaneously. Onefifth of dilutions of reverse transcribed RNA samples 
Table 1 Characteristics of healthy controls and non surviving critically ill patients

\begin{tabular}{|c|c|c|}
\hline & $\begin{array}{l}\text { Healthy } \\
\text { controls }\end{array}$ & $\begin{array}{l}\text { Critically ill patients: } \\
\text { postmortem biopsies }\end{array}$ \\
\hline Number & 20 & 61 \\
\hline Gender (no. male) & 14 & 36 \\
\hline Age (yr) (mean \pm SD) & $70 \pm 12$ & $67 \pm 15$ \\
\hline $\mathrm{BMI}\left(\mathrm{kg} / \mathrm{m}^{2}\right)($ mean $\pm \mathrm{SD})$ & $25.0 \pm 2.6$ & $24.1 \pm 3.5$ \\
\hline History of diabetes (no.) & 3 & 9 \\
\hline APACHE-II score on admission (median (IQR)) & - & 26 (20 to 34$)$ \\
\hline Admission diagnose & - & \\
\hline - Cardiovascular & & 5 \\
\hline - Gastrointestinal or liver & & 5 \\
\hline - Hematologic or oncologic & & 10 \\
\hline - Neurologic & & 3 \\
\hline - Renal & & 2 \\
\hline - Respiratory & & 30 \\
\hline - Other & & 6 \\
\hline ICU stay (median (IQR)) & 0 & $10(6$ to 19$)$ \\
\hline Cause of death in ICU & - & \\
\hline - Severe brain damage & & 2 \\
\hline - Respiratory failure & & 26 \\
\hline - Therapy resistant septic shock/cardiovascular collapse & & 14 \\
\hline - Persistent MOF after septic or SIRS induced shock & & 19 \\
\hline
\end{tabular}

APACHE II, Acute Physiology and Chronic Health Evaluation II; BMI, body mass index; ICU, intensive care unit; IQR, interquartile range; MOF, multiple organ failure; $\mathrm{SD}$, standard deviation; SIRS, systemic inflammatory response syndrome; Yrs, years.

were quantified in real time with the StepOne Plus (Applied Biosystems, Carlsbad, CA, USA), which uses TaqMan chemistry for highly accurate quantization of mRNA levels. Unknown samples were run in duplicate and individual samples with a Cycle threshold $(\mathrm{Ct})$ value

\section{Table 2 Characteristics of surviving critically ill patients}

\begin{tabular}{ll}
\hline Number & 15 \\
Gender (no. male) & 11 \\
Age (yr) (mean $\pm \mathrm{SD})$ & $56 \pm 16$ \\
$\mathrm{BMI}$ (kg/m²) (mean $\pm \mathrm{SD})$ & $28.1 \pm 5.2$ \\
APACHE-II score on admission (median (IQR)) & 30 (23 to 40) \\
Admission diagnose & \\
- Cardiac surgery & 1 \\
- Transplantation & 1 \\
- Trauma, burns or reconstructive surgery & 5 \\
- Complicated thoracic surgery & 2 \\
- Complicated vascular surgery & 1 \\
- Gastroenterologic or hepatic disease & 1 \\
- Complicated neurosurgery & 2 \\
- Hematological or oncological disease & 1 \\
- Renal disease & 1 \\
ICU stay (median (IQR)) & 22 (13 to 28) \\
Deaths during intensive care - no. (\%) & 1 (7\%)
\end{tabular}

The in vivo abdominal subcutaneous adipose tissue biopsies were sampled at Day 7 of the patients ICU stay. APACHE II, Acute Physiology and Chronic Health Evaluation II; BMI, body mass index; ICU, intensive care unit; IQR, interquartile range; MOF, multiple organ failure; SD, standard deviation; SIRS, systemic inflammatory response syndrome; Yrs, years. standard deviation greater than 0.3 were reanalyzed. Data were analyzed using the comparative Ct method. Data are expressed normalized to glyceraldehyde-3phosphate dehydrogenase (GAPDH) expression and as a fold change of the mean of the controls. GAPDH, arginase-1, IL-10, iNOS, CD163, IL-4, IL-13 and TNF- $\alpha$ gene expression assays from Applied Biosystems were used.

\section{Serum analyses}

Serum levels of IFN- $\gamma$, IL-4, IL-10 and IL-13 were measured with high sensitivity ELISAs (eBioscience, San Diego, CA, USA) according to the manufacturer's protocol.

\section{Immunoblot analysis}

Tissue samples were weighed and homogenized with a Precellys 24 machine using CK14 tubes containing ceramic beads at 6,000 rpm for one cycle of $30 \mathrm{sec}$ in lysis buffer containing phosphatase inhibitors. The homogenates were centrifuged for 10 minutes at 5,000 rpm and $4^{\circ} \mathrm{C}$. The protein content in the homogenate was determined with a Coomassie Protein Assay Reagent (Thermo Scientific Pierce, Rockford, IL, USA). An equal amount of protein was loaded for each sample and homogenates were separated by denaturating SDSPAGE and immunoblotted with a specific Ab against peroxisome proliferator-activated receptor- $\gamma$ (PPAR $\gamma)$ 
(ABCAM, Cambridge, UK), and with a species-specific HRP-conjugated secondary Ab. All blots were analyzed using Image Master Software (GE Healthcare Europe, Chalfont St. Giles, UK).

\section{Statistics}

We used ANOVA and unpaired t-test for normally distributed data and the non-parametric Kruskal-Wallis and Mann-Whitney $U$ test when data appeared to be not normally distributed. Statistical significance was considered when $P$-values were $\leq 0.05$.

\section{Results}

\section{Characterization of the macrophages}

We described earlier that subcutaneous and visceral adipose tissue biopsies from critically ill patients display a large number of CD68 positive cells, which is a general macrophage marker. This was in sharp contrast with biopsies from healthy controls where only occasionally some CD68 positive cells were observed [1]. Positive cells displayed macrophage morphology and were found scattered throughout the adipose tissue (Figure 1).

Depending on the activation, macrophages can polarize to a M1- or M2- phenotype. Each phenotype expresses specific markers, allowing the identification of the phenotype. TNF- $\alpha$ and iNOS are specific markers for the M1 phenotype. In a selection of 61 human postmortem adipose tissue biopsies, TNF- $\alpha$ gene expression was decreased in both the subcutaneous and visceral depot, compared to healthy controls (Figure 2A). We could also demonstrate a decreased iNOS gene expression in visceral adipose tissue (from 0.81 (0.54 to 1.3$)$ in healthy individuals to 0.34 (0.23 to 0.81 ) median (IQR) in non-surviving critically ill patients, $P=0.0095$ ), with unaltered levels in the subcutaneous adipose tissue of nonsurviving critically ill patients (from 0.91 ( 0.70 to $1.22)$ in health, to 0.82 (0.31 to 2.05$)$ in critical illness, $P$ $=0.9)$. These observations suggest that the macrophages we identified in adipose tissue of critically ill patients are not of the pro-inflammatory M1-type.

Therefore, we tested adipose tissue expression level of the specific M2 marker arginase-1 in the same selection of 61 nonsurviving critically ill patients. In contrast with the M1 markers, arginase-1 gene expression was increased several-fold in both visceral and subcutaneous depots (Figure 2B). Two other markers for M2 phenotype macrophages, CD163 and IL-10, were comparably elevated in the human postmortem visceral and subcutaneous adipose tissue biopsies (Figure 2C, D). Because gene expression levels were measured in total adipose tissue, we confirmed the cell specificity of the M2-markers with immunostaining in a random selection of the available postmortem biopsies. In the nonsurviving critically ill patients, 9 out of 10 omental adipose tissue biopsies and 10 out of 10 subcutaneous adipose tissue biopsies stained positive for CD163 whereas in healthy controls none of the tested omental $(n=10)$ nor subcutaneous $(n=10)$ biopsies stained positive for CD163. Positive CD163 staining pattern in the biopsies from critically ill patients was comparable to the CD68 staining pattern (Figure 2E).

Functionally, M2 macrophages will produce high levels of IL-10, whereas iNOS expression and concomitant NO-production might be reduced. Indeed, in serum

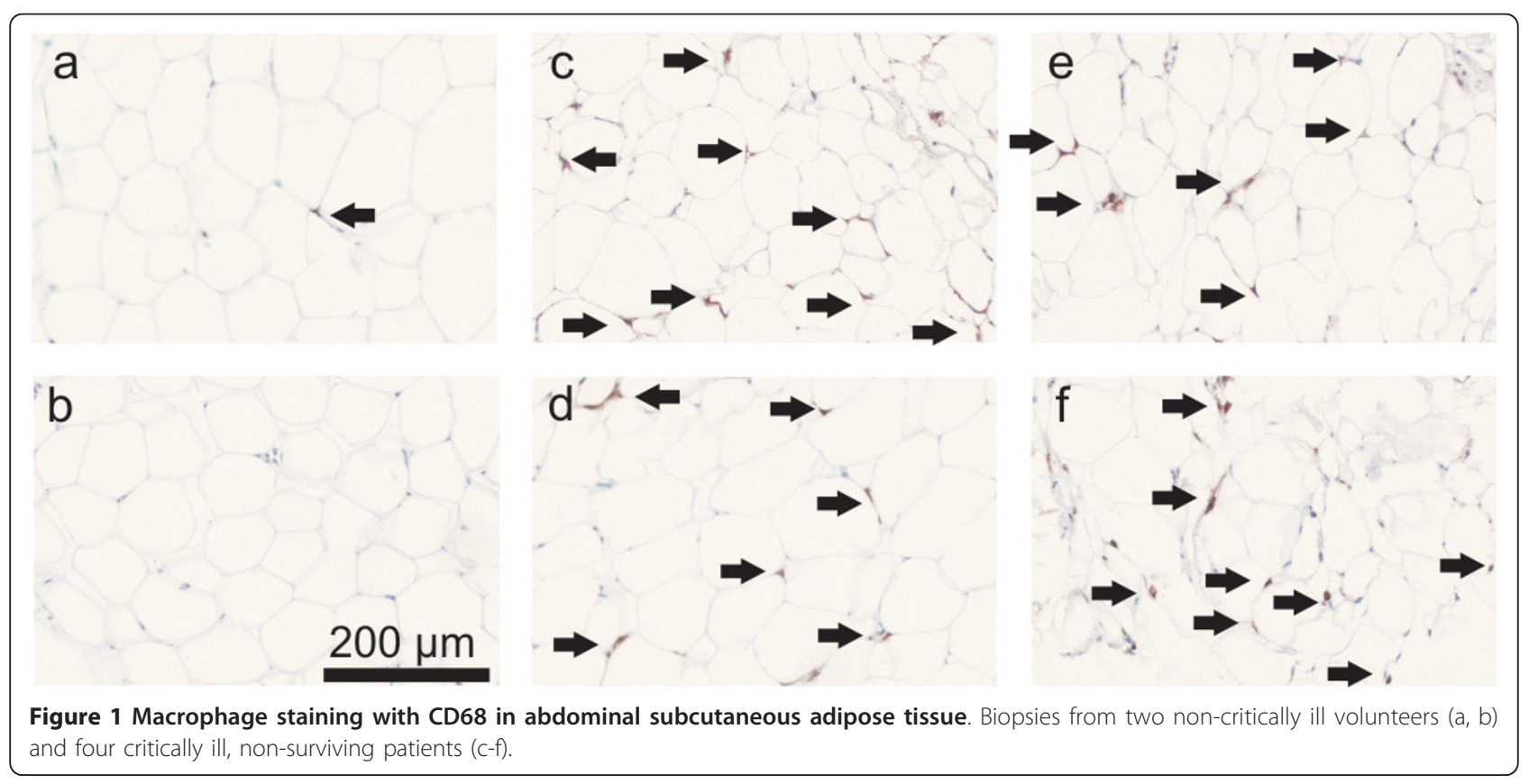




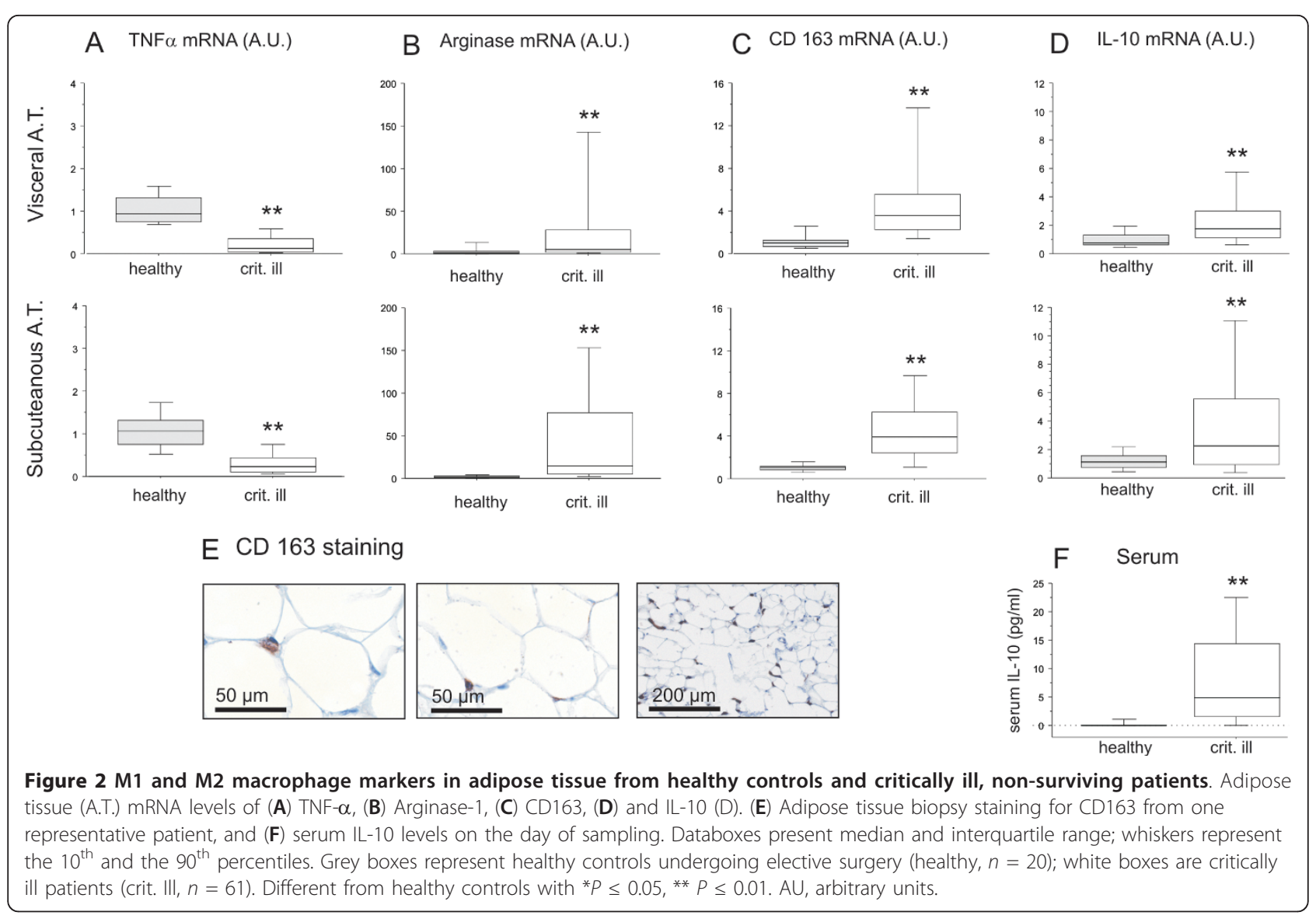

samples taken on the day of the biopsy, IL-10 was clearly elevated in the patients compared to healthy controls (Figure 2F). However, the levels did not correlate significantly with tissue gene expression level, pointing to other IL-10 sources besides adipose tissue residing macrophages.

\section{Possible triggers for macrophage accumulation}

The primary trigger for M1 type activation is IFN- $\gamma$. In serum samples collected on the day of the biopsy, IFN- $\gamma$ levels were low (mean \pm SE $1.77 \pm 0.49 \mathrm{pg} / \mathrm{ml}$ ) in critically ill patients, but not different from healthy control samples $(P=0.9)$. The most common activators of M2 macrophages are the anti-inflammatory cytokines IL-4 and IL-13. IL-4 serum levels were however below detection limit (90\% of the patients) or very low. IL-13 levels were low $(6.24 \pm 2.70 \mathrm{pg} / \mathrm{ml})$, and not different from healthy control samples $(P=0.9)$. Adipocytes and residing macrophages can also locally produce cytokines, which might trigger M2 type activation. Gene expression of IL-4 and of IL-13 was low to undetectable in both visceral and omental adipose tissue postmortem biopsies and no difference could be detected from healthy volunteers.
More downstream of cytokine activation, PPAR $\gamma$, which is a nuclear receptor expressed in high levels in adipose tissue, is a possible trigger for M2 polarization. It plays a pivotal part in adipogenesis, lipid biosynthesis, insulin sensitivity, but has also been demonstrated to stimulate the formation of M2 macrophages. IL-4 and IL-13 are known to activate PPAR $\gamma$. With Western blotting, we could clearly demonstrate increased levels of PPAR $\gamma$ in both subcutaneous and visceral postmortem adipose tissue biopsies from critically ill patients, compared to healthy controls (Figure 3).

\section{Confirmation in vivo}

We were able to collect in vivo small needle biopsies from abdominal subcutaneous adipose tissue in 15 critically ill patients at Day 7 of their ICU stay. Of the 15 patients from which we sampled in vivo biopsies, 14 patients survived their ICU and hospital stay. Only one patient died in the ICU, and this was after 121 days (114 days after the day of the biopsy).

Paraffin sections of the in vivo biopsies stained positive for CD68 (Figure 4A) and CD163 (Figure 4B), confirming our findings of the postmortem biopsies. We also quantified arginase- 1 and TNF- $\alpha$ gene 

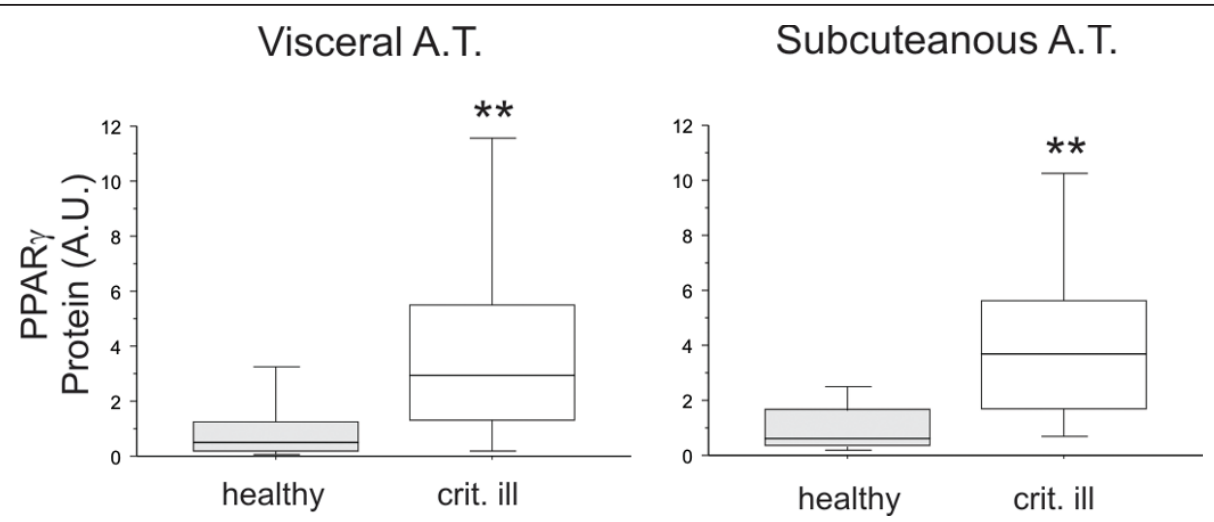

Figure 3 Adipose tissue levels of protein PPAR $\gamma$ from healthy controls and critically ill, non-surviving patients. Databoxes present median and interquartile range; whiskers represent the $10^{\text {th }}$ and the $90^{\text {th }}$ percentiles. Grey boxes represent healthy controls undergoing elective surgery (healthy, $n=20$ ); white boxes are critically ill patients (crit. III, $n=61$ ). Different from healthy controls with ** $P \leq 0.01$. AT, adipose tissue; $\mathrm{AU}$, arbitrary units.

expression in the in vivo biopsies together with healthy control samples. Confirming our findings in the nonsurviving patients, we could demonstrate in these surviving patients a clearly increased gene expression of the M2-marker arginase-1 (Figure 4C), whereas TNF- $\alpha$ was not altered compared to healthy controls (healthy controls 0.98 (0.75 to 1.37), critically ill patients 0.90 (0.35 to 1.83 ), $P=0.37$ ). Samples were also used for protein analysis, with which we could confirm an increase in PPAR $\gamma$ compared to healthy controls (Figure 4D).

\section{Impact of insulin or steroid treatment}

Treatment with insulin or corticosteroids might influence the inflammatory state of the patient and consequently influence macrophage polarization. The patients from which we studied postmortem biopsies were all enrolled in a randomized controlled trial on blood glucose control [8]. From the 61 studied nonsurviving patients, 33 patients were on conventional insulin regimen, which resulted in mean blood glucose levels of $157 \pm 4 \mathrm{mg} / \mathrm{dl}$ (mean $\pm \mathrm{SE}), 28$ patients were on intensive insulin therapy which resulted in mean blood

\section{A CD 68 staining}

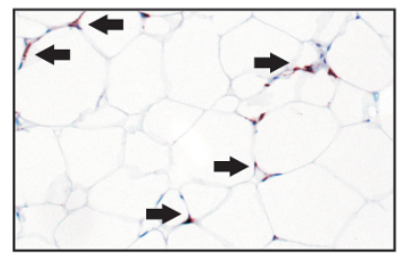

\section{B CD 163 staining}

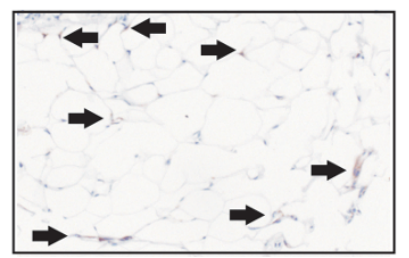

C



*

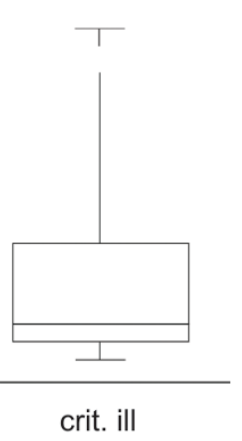

D

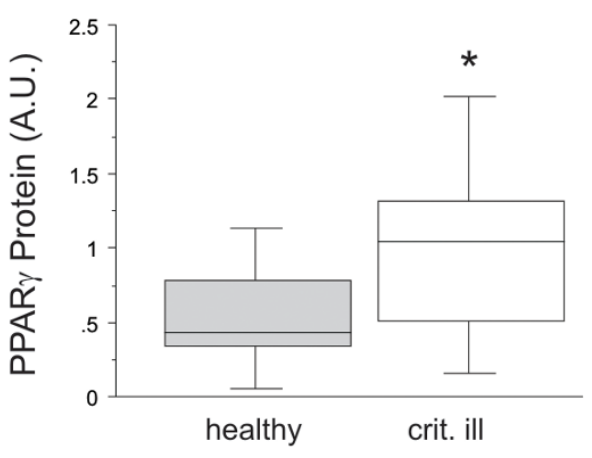

Figure 4 Macrophage markers in adipose tissue from (healthy controls and critically ill, surviving patients. Positive CD68 (A) and CD163 (B) staining in in vivo abdominal subcutaneous biopsies from critically ill patients. (C) Adipose tissue levels of arginase-1 gene expression. (D) Adipose tissue levels of protein PPAR $\gamma$. Databoxes present median and interquartile range; whiskers represent the $10^{\text {th }}$ and the $90^{\text {th }}$ percentiles. Grey boxes represent healthy controls undergoing elective surgery (healthy, $n=20$ ); white boxes are critically ill patients from which in vivo biopsies were collected (crit. III, $n=15$ ). Different from healthy controls with * $P \leq 0.05$. AU, arbitrary units. 
glucose levels of $110 \pm 3 \mathrm{mg} / \mathrm{dl}$. Both patient groups displayed elevated insulin levels on the day of biopsy, 12.1 (7.0 to 31.2) $\mathrm{mIU} / \mathrm{l}$ (median (IQR)) for the conventional group, 29.3 (10.2 to 83.2$) \mathrm{mIU} / \mathrm{l}$ for the intensive insulin treated group, and only 6.2 (6.0 to 7.4$) \mathrm{mIU} / \mathrm{l}$ for the healthy control group. Although the two treatment groups displayed different glucose levels and different circulating insulin levels, this did not result in a different expression level of any of the tested macrophage markers. Also, the tested circulating cytokines did not differ between the two treatment groups. Although insulin is known for its anti-inflammatory actions $[9,10]$, insulin therapy had apparently no impact on either macrophage marker expression profile or cytokine levels. This confirms earlier findings in which insulin therapy had no [11] or very minor [12] impact on circulating cytokines, irrespective of its anti-inflammatory actions [10].

In the postmortem patient population, 51 out of 61 patients $(84 \%)$ received steroids during their ICU stay. In the in vivo patient population, 6 out of 15 patients (40\%) received steroids before the biopsy sampling. Treated and untreated patients displayed similar levels for the tested macrophage markers and circulating cytokines. Treatment with steroids thus appeared not to affect macrophage polarization in adipose tissue.

\section{Discussion}

In this study, we demonstrated that critical illness induces an accumulation of alternatively active M2 macrophages in adipose tissue. High levels of PPAR $\gamma$ in the adipose tissue of critically ill patients could explain this accumulation, rather than high circulating cytokine levels.

The activation of M1 macrophages is a classical feature of cellular immunity to infection while the alternative activation of M2 macrophages is considered to have a role in humoral immunity and repair. Alternatively activated M2 macrophages have been implicated in immunity, inflammation, allergy, parasitic infections, repair, metabolic functions and malignancy [6]. Alternatively activated macrophages express high levels of the enzyme arginase-1 [13]. Arginase-1 was classically an enzyme considered to be exclusively expressed in the liver, but is now recognized to also occur in cells of the immune system. Arginase- 1 is the enzyme that produces ornithine, the precursor of polyamines and proline. Polyamines participate in a variety of cellular processes, such as cell proliferation and tissue regeneration [14]. Activation of arginase- 1 also counteracts iNOS action by competing for the same substrate arginine, thereby inhibiting the biosynthesis of nitric oxide [15]. CD163 and IL-10, two other markers of alternative macrophage activation, were also up-regulated in adipose tissue of critically ill patients $[16,17]$. CD163 is the scavenging receptor for hemoglobin, exclusively expressed by monocytes and tissue macrophages $[17,18]$. Macrophages are the primary scavengers of hemoglobin after systemic hemolysis and during wound healing, two processes which are often ongoing during critical illness. IL-10 is a strong anti-inflammatory cytokine that conditions the activation and function of immune cells, selectively blocks the expression of pro-inflammatory genes and enhances the expression of anti-inflammatory molecules [19]. In critically ill patients, adipose tissue IL-10 expression, as well as IL-10 in circulation, was clearly elevated. We could not, however, demonstrate a clear association between circulating IL-10 levels and expression levels in adipose tissue, which suggests other possible sources for IL-10. Possibly, the produced IL-10, but also CD163 and arginase in adipose tissue macrophages only play a paracrine role, thereby preventing adipose tissue injury from excess inflammation and insulin resistance. Remarkably, circulating mononuclear cells from critically ill patients also appear to be switched to the M2-phenotype [20,21].

Once the polarization state of the macrophages was determined, we tried to identify the trigger for the M2 polarization in adipose tissue of critical illness. Macrophages are polarized to the M1 state through the classical activation pathway by the $T_{H} 1$ cytokine IFN- $\gamma$, while the alternative activation with $\mathrm{T}_{\mathrm{H}} 2$ cytokines IL- 4 and IL-13 polarizes macrophages to the M2 phenotype $[6,13,22]$. In our experimental setup, IFN- $\gamma$, IL-4 or IL-13 was not upregulated in circulation. Also, locally produced cytokines might trigger macrophage polarization. We, however, did not find an up-regulation of IL-4 or IL-13 expression. Our methodology in which we measured gene expression in total adipose tissue might possibly not be sensitive enough to measure a mild up-regulation of IL4 or IL13 only in adipocytes. However, critically ill patients often suffer from systemic inflammatory response syndrome (SIRS) or sepsis, associated with high circulating levels of several pro-inflammatory and anti-inflammatory cytokines. Possibly, it is this cocktail of cytokines, which is responsible for the pro-inflammatory activation of macrophages in adipose tissue.

We were able to identify a more downstream activator of M2 polarization. PPAR $\gamma$ is a transcription factor that has been characterized as a key signal in alternative M2 macrophage activation $[13,23]$. We clearly found increased PPAR $\gamma$ protein levels in adipose tissue of critically ill patients, both in postmortem biopsies and in vivo. Although it has been demonstrated that IL-4 and IL-13 can activate PPAR $\gamma$, other possible activators for PPAR $\gamma$ are fatty acids and prostaglandines $[13,24,25]$. Possibly high circulating lipid levels, often observed in critically ill patients, play a role in the observed PPAR $\gamma$ activation [26-28]. 
The following limitation in the study design should be highlighted. Because the available biopsies were all snapfrozen at the time of biopsy, we were not able to isolate adipocytes from the stromal cell fraction. Gene and protein expression were, therefore, quantified in whole adipose tissue homogenates.

\section{Conclusions}

In conclusion, we demonstrated that unlike obesity, critical illness evokes accumulation of alternatively activated M2 macrophages in adipose tissue. M2 accumulation in the adipose tissue could be considered as a beneficial response promoting anti-inflammatory actions, wound healing and scavenging of hemoglobin. Whether or not the M2 macrophages only play a local role in the adipose tissue, or are a source of polyamines and soluble CD163 in the circulation cannot be concluded from this study. Possibly also other tissues, such as the liver, might display increased macrophage infiltration and M2 polarization during critical illness, for which further study is needed.

\section{Key messages}

- Irrespective of the admission diagnosis, prolonged critically ill patients display accumulation of macrophages in adipose tissue.

- These tissue macrophages display characteristics of alternatively activated M2 macrophages.

- The key trigger for this accumulation might be an increase in PPAR $\gamma$ activity.

\begin{abstract}
Abbreviations
APACHE II: Acute Physiology and Chronic Health Evaluation II; AT: adipose tissue; AU: arbitrary units; BMI: body mass index; GAPDH: glyceraldehyde-3phosphate dehydrogenase; IL: interleukin; iNOS: inducible nitric-oxide synthase; IQR: interquartile range; MOF: multiple organ failure; PPARY: peroxisome proliferator-activated receptor- $\gamma$; SD: standard deviation; SE: standard error; SIRS: systemic inflammatory response syndrome; TNF: tumor necrosis factor; Yrs: years.
\end{abstract}

\section{Acknowledgements}

We thank the patients, control participants and family members for participating in the study. We are very grateful for the expert technical assistance of Eric Ververs. We wish to acknowledge Prof. Alexander Wilmer and Prof. Greet Hermans for their help with the collection of the biopsies. This work was supported by the Fund for Scientific Research Flanders, Belgium (FWO), by the Research Council of the Katholieke Universiteit Leuven (GOA) and by long term structural funding - Methusalem funding by the Flemish Government. $\mathrm{LL}$ is a Postdoctoral Fellow and JG is a PhD fellow for the FWO.

\section{Author details}

'Laboratory and Department of Intensive Care Medicine, K.U.Leuven, Herestraat 49, 3000 Leuven, Belgium. ${ }^{2}$ Department of Abdominal Surgery, K. U.Leuven, Herestraat 49, 3000 Leuven, Belgium.

\section{Authors' contributions}

LL designed and coordinated the study, participated in the data collection, analyzed the results and drafted the manuscript. MM participated in the design of the study and helped to draft the manuscript. JG, AD and SD participated in the design of the study and the collection of the biopsies. $\mathrm{Cl}$ participated in the molecular gene expression studies. SVP participated in the molecular gene expression studies and immunostainings. GV participated in the study design and coordination and helped to draft the manuscript. All authors read and approved the final manuscript for publication.

\section{Competing interests}

The authors declare that they have no competing interests.

Received: 29 June 2011 Revised: 9 August 2011

Accepted: 21 October 2011 Published: 21 October 2011

\section{References}

1. Langouche L, Vander Perre S, Thiessen S, Gunst J, Hermans G, D'Hoore A, Kola B, Korbonits M, Van den Berghe G: Alterations in adipose tissue during critical illness: An adaptive and protective response? Am J Respir Crit Care Med 2010, 182:507-516.

2. Weisberg SP, McCann D, Desai M, Rosenbaum M, Leibel RL, Ferrante AW Jr: Obesity is associated with macrophage accumulation in adipose tissue. $J$ Clin Invest 2003, 112:1796-1808.

3. Xu H, Barnes GT, Yang Q, Tan G, Yang D, Chou CJ, Sole J, Nichols A, Ross JS, Tartaglia LA, Chen H: Chronic inflammation in fat plays a crucial role in the development of obesity-related insulin resistance. J Clin Invest 2003, 112:1821-1830.

4. Lumeng CN, Bodzin JL, Saltiel AR: Obesity induces a phenotypic switch in adipose tissue macrophage polarization. J Clin Invest 2007, 117:175-184.

5. Fujisaka S, Usui I, Bukhari A, Ikutani M, Oya T, Kanatani Y, Tsuneyama K, Nagai Y, Takatsu K, Urakaze M, Kobayashi M, Tobe K: Regulatory mechanisms for adipose tissue $M 1$ and $M 2$ macrophages in dietinduced obese mice. Diabetes 2009, 58:2574-2582.

6. Gordon S, Martinez FO: Alternative activation of macrophages: mechanism and functions. Immunity 2010, 32:593-604

7. Odegaard Jl, Chawla A: Mechanisms of macrophage activation in obesity-induced insulin resistance. Nat Clin Pract Endocrinol Metab 2008, 4:619-626.

8. Van den Berghe G, Wilmer A, Hermans G, Meersseman W, Wouters PJ, Milants I, Van Wijngaerden E, Bobbaers $H$, Bouillon R: Intensive insulin therapy in the medical ICU. N Engl J Med 2006, 354:449-461.

9. Dandona P, Aljada A, Dhindsa S, Garg R: Insulin as an anti-inflammatory and antiatherosclerotic hormone. Clin Cornerstone 2003, , Suppl 4: S13-20.

10. Hansen TK, Thiel S, Wouters PJ, Christiansen JS, Van den Berghe G: Intensive insulin therapy exerts antiinflammatory effects in critically ill patients and counteracts the adverse effect of low mannose-binding lectin levels. J Clin Endocrinol Metab 2003, 88:1082-1088.

11. Langouche L, Meersseman W, Vander Perre S, Milants I, Wouters PJ, Hermans G, Gjedsted J, Hansen TK, Arnout J, Wilmer A, Schetz M, Van den Berghe G: Effect of insulin therapy on coagulation and fibrinolysis in medical intensive care patients. Crit Care Med 2008, 36:1475-1480.

12. Langouche L, Vanhorebeek I, Vlasselaers D, Vander Perre S, Wouters PJ, Skogstrand K, Hansen TK, Van den Berghe G: Intensive insulin therapy protects the endothelium of critically ill patients. J Clin Invest 2005, 115:2277-2286.

13. Odegaard JI, Ricardo-Gonzalez RR, Goforth MH, Morel CR, Subramanian V, Mukundan L, Red Eagle A, Vats D, Brombacher F, Ferrante AW, Chawla A: Macrophage-specific PPARgamma controls alternative activation and improves insulin resistance. Nature 2007, 447:1116-1120.

14. Moinard C, Cynober L, de Bandt JP: Polyamines: metabolism and implications in human diseases. Clin Nutr 2005, 24:184-197.

15. Munder M: Arginase: an emerging key player in the mammalian immune system. Br J Pharmacol 2009, 158:638-651.

16. Kambayashi T, Jacob CO, Strassmann G: IL-4 and IL-13 modulate IL-10 release in endotoxin-stimulated murine peritoneal mononuclear phagocytes. Cell Immunol 1996, 171:153-158.

17. Kristiansen M, Graversen JH, Jacobsen C, Sonne O, Hoffman HJ, Law SK, Moestrup SK: Identification of the haemoglobin scavenger receptor. Nature 2001, 409:198-201.

18. Schaer DJ, Schaer CA, Buehler PW, Boykins RA, Schoedon G, Alayash Al, Schaffner $A: C D 163$ is the macrophage scavenger receptor for native and chemically modified hemoglobins in the absence of haptoglobin. Blood 2006, 107:373-380. 
19. Moore KW, de Waal MR, Coffman RL, O'Garra A: Interleukin-10 and the interleukin-10 receptor. Annu Rev Immunol 2001, 19:683-765.

20. Ochoa JB, Bernard AC, O'Brien WE, Griffen MM, Maley ME, Rockich AK, Tsuei BJ, Boulanger BR, Kearney PA, Morris SM Jr: Arginase I expression and activity in human mononuclear cells after injury. Ann Surg 2001, 233:393-399.

21. Bryk JA, Popovic PJ, Zenati MS, Munera V, Pribis JP, Ochoa JB: Nature of myeloid cells expressing arginase 1 in peripheral blood after trauma. $J$ Trauma 2010, 68:843-852.

22. Herbert DR, Holscher C, Mohrs M, Arendse B, Schwegmann A, Radwanska M, Leeto M, Kirsch R, Hall P, Mossmann H, Claussen B, Forster I, Brombacher F: Alternative macrophage activation is essential for survival during schistosomiasis and downmodulates Thelper 1 responses and immunopathology. Immunity 2004, 20:623-635.

23. Stienstra R, Duval C, Keshtkar S, van der Laak J, Kersten S, Müller M: Peroxisome proliferator-activated receptor gamma activation promotes infiltration of alternatively activated macrophages into adipose tissue. $J$ Biol Chem 2008, 283:22620-22627.

24. Xu HE, Lambert MH, Montana VG, Parks DJ, Blanchard SG, Brown PJ, Sternbach DD, Lehmann JM, Wisely GB, Willson TM, Kliewer SA, Milburn MV Molecular recognition of fatty acids by peroxisome proliferator-activated receptors. Mol Cell 1999, 3:397-403.

25. Forman BM, Tontonoz P, Chen J, Brun RP, Spiegelman BM, Evans RM: 15Deoxy-delta 12, 14-prostaglandin J2 is a ligand for the adipocyte determination factor PPAR gamma. Cell 1995, 83:803-812.

26. Grunfeld C, Feingold KR: Tumor necrosis factor, cytokines, and the hyperlipidemia of infection. Trends Endocrinol Metab 1991, 2:213-219.

27. Lind $L$, Lithell $H:$ Impaired glucose and lipid metabolism seen in intensive care patients is related to severity of illness and survival. Clin Intensive Care 1994, 5:100-105.

28. Mesotten D, Swinnen JV, Vanderhoydonc F, Wouters PJ, Van den Berghe G: Contribution of circulating lipids to the improved outcome of critical illness by glycemic control with intensive insulin therapy. J Clin Endocrinol Metab 2004, 89:219-226.

\section{doi:10.1186/cc10503}

Cite this article as: Langouche et al:: Critical illness induces alternative activation of M2 macrophages in adipose tissue. Critical Care 2011 15: R245.

\section{Submit your next manuscript to BioMed Central and take full advantage of:}

- Convenient online submission

- Thorough peer review

- No space constraints or color figure charges

- Immediate publication on acceptance

- Inclusion in PubMed, CAS, Scopus and Google Scholar

- Research which is freely available for redistribution

Submit your manuscript at www.biomedcentral.com/submit 